\title{
DIMENSÕES DO EXCESSO E DE REALIDADE: REFLEXÕES COM BASE EM UMA EXPERIÊNCIA DE ESCUTA
}

DIMENSIONS OF EXCESS AND REALITY: REFLECTIONS BASED ON A LISTENING EXPERIENCE

DIMENSIONES DEL EXCESO Y DE REALIDAD: REFLEXIONES DESDE UNA EXPERIENCIA DE ESCUCHA

\author{
Renata Freitas Ribas* \\ Laura de Oliveira Tomasi** \\ Mônica Medeiros Kother Macedo ${ }^{* * *}$
}

\begin{abstract}
RESUMO
Em psicanálise, sabe-se que a vivência de um trauma, seja ele real ou fantasiado, causa impactos importantes no psiquismo. Este trabalho propóe, por uma vinheta clínica, a reflexão a respeito dos efeitos do traumático advindo do histórico vivencial e da realidade psíquica do sujeito. No desenvolvimento das proposições deste artigo, utiliza-se de vinhetas de um caso clínico a fim de ilustrar a inter-relação entre experiências da realidade externa e as marcas decorrentes desta na realidade interna. A história de Marta permite apresentar contribuições da psicanálise a respeito de trauma psíquico. Acredita-se ser a escuta analítica um recurso diante das manifestações de dor psíquica oriundas do excesso traumático. $\mathrm{Na}$ instauração de condiçóes de tramitação psíquica e de atribuição de sentido às experiências de dor, é possível acompanhar a construção de novas possibilidades de devir ao sujeito psíquico.
\end{abstract}

Palavras-chave: Psicanálise. Trauma. Realidade psíquica. Realidade externa. Escuta.

\section{ABSTRACT}

In psychoanalysis, it is known that the experience of a trauma, either real or fantasized, causes significant impact on the psychism. This paper proposes, based on a clinical vignette, reflection on the effects of the trauma coming from the historical existential and psychic reality of the subject. In the

\footnotetext{
Texto recebido em 8 de julho de 2013 e aprovado para publicação em 25 de setembro de 2014.

Mestra em Psicologia Clínica pelo Programa de Pós-Graduação em Psicologia da Faculdade de Psicologia da Pontifícia Universidade Católica do Rio Grande do Sul (PUCRS); psicóloga; membro associado da Sigmund Freud Associação Psicanalítica. Endereço: Avenida Venâncio Aires, 169, ap. 704 - Cidade Baixa, Porto Alegre-RS, Brasil. CEP: 90040-191. E-mail: renataribas.psico@yahoo.com.br.

** Mestra em Psicologia Clínica pela PUCRS; psicóloga; psicanalista em formação pelo Centro de Estudos Psicanalíticos de Porto Alegre (CEP de PA); psicóloga concursada na Secretaria de Saúde do Município de Glorinha-RS. Endereço: Rua Dr. Barcelos, 799, ap. 201 - Tristeza, Porto Alegre-RS, Brasil. CEP: 91910-251. E-mail: lauratomasi08@hotmail.com.

*** Doutora em Psicologia; professora titular da Graduação e da Pós-Graduação no Centro de Psicologia, Escola de Humanidades da PUCRS; coordenadora do Grupo de Pesquisa Fundamentos e Intervenções em Psicanálise do Programa de Pós-Graduação em Psicologia (PPGP-PUCRS); psicóloga; psicanalista. Endereço: Rua Florêncio Ygartua, 69, ap. 307 - Moinhos de Vento, Porto Alegre-RS, Brasil. CEP: 90430-010. E-mail: monicakm@pucrs.br.
} 
development of the propositions, this article uses vignettes of a clinical case to illustrate the interrelationship between experiences of external reality and brands arising from this in the internal reality. The story of Marta allows us to discuss contributions of psychoanalysis concerning the psychical trauma. It is believed that analytical listening is a fundamental resource for the demonstration of psychic pain, which originated from the traumatic excess. From the establishment of conditions of psychic processing and assigning meaning to the experiences of pain it is possible to follow the construction of the new opportunities of becoming a psychic subject.

Keywords: Psychoanalysis. Trauma. Psychic reality. External reality. Listening.

\section{RESUMEN}

En el psicoanálisis, se sabe que la experiencia del trauma, sea real o fantaseada, provoca un impacto significativo en la psique. En este trabajo se propone, a partir de una viñeta clínica la reflexión sobre los efectos del trauma que viene del histórico vivencial y de la realidad psíquica del sujeto. En la elaboración de las propuestas de este artículo se utilizan viñetas de un caso clínico para ilustrar la interrelación entre las experiencias de la realidad externa y las huellas resultantes de ésta en la realidad interna. La historia de Marta permite discutir las contribuciones del psicoanálisis sobre el trauma psíquico. Se cree que la escucha analítica es un recurso fundamental frente las manifestaciones de dolor psíquico que viene de la vigencia del exceso traumático. En el establecimiento de las condiciones de procesamiento psíquico y de asignación de sentido a las experiencias del dolor es posible seguir la construcción de nuevas posibilidades del devenir del sujeto psíquico.

Palabras clave: Psicoanálisis. El trauma. La realidad psíquica. La realidad externa. Escucha.

\section{INTRODUÇÃO}

E

m psicanálise, o termo "realidade" tem amplo significado, diferentemente de seu entendimento em nível do senso comum. A partir de suas proposições metapsicológicas, Sigmund Freud descentra o sujeito da consciência e propõe a existência do sujeito de inconsciente. Dessa forma, com a descoberta freudiana, o sujeito se depara não somente com efeitos cognoscíveis de uma realidade externa, mas passa a estar à mercê de efeitos e intensidade que habitam sua realidade psíquica.

O conceito de realidade psíquica surge em função das limitações a respeito da teoria da sedução, proposta inicialmente por Freud para dar conta da etiologia 
da patologia histérica (Laplanche $\&$ Pontalis, 2010). Assim, as fantasias passam a ter um papel tão relevante na produção de padecimentos quanto o que se apresentou a Freud $(1897 / 1996)^{1}$ a respeito de um trauma real. No entanto, apesar da reformulação teórica sobre o real na cena de sedução, o relevante impacto psíquico negativo decorrente de vivências traumáticas (reais ou não) nunca foi abandonado por Freud (Goldgrub, 1988).

Considerando o entendimento de realidade psíquica, Hornstein (2008) discorre sobre a importância do histórico vivencial na constituição do sujeito psíquico, enfatizando a necessidade da presença estruturante de um outro primordial e de sua função de inaugurar a sexualidade na criança. Logo, o processo de formação das estruturas psíquicas "implica que a história de cada sujeito particular ficou inscrita de algum modo em sua estrutura psíquica" (Aslan, 1996, p. 71). Com base nessas consideraçôes, reafirma-se o valor do histórico vivencial no processo de subjetivação e de constituição psíquica, enfatizando-se a condição primordial do encontro com o outro humano.

Conforme a descrição de Freud (1914/1996) a respeito do processo de constituição psíquica instaurado desde que a criança nasce, por meio do polo perceptivo, vão se inscrevendo marcas, registros mnêmicos no psiquismo em construção. No início da vida, a mãe tem o papel de protetora do bebê, assegurando que o nível de excitação externa seja tolerável e ela seja passível de ser elaborada psiquicamente. A mãe se vale de seus próprios recursos psíquicos, a fim de auxiliar o bebê frente à sua condição inerente de desamparo (Freud, 1914). Nesse encontro primordial, frente à demanda advinda da condição de desamparo, ocorre a realização da ação específica que atenda às necessidades do bebê. Moraes e Macedo (2011) abordam a complexidade dessa experiência explorando os singulares elementos presentes nessa vivência de satisfação que a criança experimenta ao ver suas demandas atendidas pela mãe. De um lado, estão as intensidades experimentadas pelo bebê, o qual é incapaz de atribuir-lhes sentido devido ao estado incipiente de seu psiquismo; de outro, encontra-se o adulto, que, ao tentar suprir as necessidades do bebê, também lhe oferta algo que é da ordem de sua sexualidade.

Foi Sigmund Freud (1895) quem inaugurou um pensamento complexo a respeito da singular condição humana que coloca como imperativo o encontro com o outro. Assim, no atendimento às necessidades próprias à sobrevivência do organismo físico, ocorrerem experiências fundamentais para a constituição do sujeito psíquico. No texto freudiano, não há dúvidas sobre a importância das condições psíquicas daquele que exerce a ajuda, bem como a respeito da

A primeira data indica o ano de publicação original da obra, e a segunda, a edição consultada pelo autor. Esta somente será pontuada na primeira citação da obra no texto. Nas seguintes, será registrada apenas a data de publicação original. 
necessidade de esse tomar a criança como objeto de investimento amoroso a fim de captar e traduzir suas demandas singulares. Assim, ressalta-se a relevância desse encontro primordial e do acolhimento amoroso, por parte da mãe, desse bebê que é incapaz de, por si só, sanar as próprias necessidades (Freud, 1895). Cabe à função materna exercer ações específicas que dão conta daquilo que o bebê não pode suprir em si mesmo.

No cenário descrito, percebem-se as inerentes condições de desamparo da criança atendidas no encontro com um outro que lhe empresta seus próprios recursos psíquicos a fim de auxiliá-lo (Freud, 1914). Conforme Moraes e Macedo (2011), a criança necessita de que a mãe seja capaz de traduzir e interpretar suas demandas, porém reconhecendo a diferença que sua existência implica. Traduzir nesse momento significa reconhecer o que a criança não pode fazer por si mesma, mas não significa apropriar-se de sua condição de existir como sujeito separado da mãe. Conforme lhe é outorgado o direito de ser, a criança vai criando representaçóes simbólicas a fim de poder a controlar os estímulos e organizar sua excitação e, assim, aos poucos, a mãe poderá abandonar essa função necessária, mas finita.

$\mathrm{Na}$ consideração à oferta materna que extrapola o apaziguamento das necessidades autoconservativas da criança, a psicanálise ressalta a complexidade necessária ao processo de organização psíquica. Bleichmar (2005), ao enfatizar as proposições freudianas, destaca a importância do papel exercido pelo outro no processo de constituição de um sujeito psíquico. Segundo a autora, ao atender às necessidades inerentes à condição de desamparo físico da cria humana, o outro o alimenta não somente do ponto de vista fisiológico, mas também de sensações, sentimentos, preceitos morais e ideologias. A contribuição dessa autora alinha-se aos aportes freudianos e não deixa dúvidas sobre a importância das experiências do campo intersubjetivo no processo de construção do sujeito psíquico.

Nessa direção, este artigo aborda o tema do excesso no histórico vivencial do sujeito e seus importantes efeitos traumáticos na vida do sujeito. Para tal, com base no relato de um material clínico, são desenvolvidas reflexôes a fim de ilustrar a essencial relação entre as experiências de vida e as condições da realidade intrapsíquica. Por essa experiência de escuta, são enfatizados os efeitos psíquicos decorrentes da condição na qual o excesso marca a singularidade da história de uma paciente.

A proposição do caso clínico como material de discussão sobre os aportes da psicanálise como teoria, método e técnica se fundamenta nas proposições de Magtaz e Berlinck (2012) a respeito da relevância desse tipo de material para a pesquisa em psicanálise. $\mathrm{O}$ relato de caso representa a possibilidade de trabalho 
diante de um problema de investigação e constitui um alicerce para pesquisa (Magtaz \& Berlinck, 2012). O material desenvolvido a partir de um relato de caso aborda, segundo os autores, o que foi impactante ao clínico diante de seu estado de atenção flutuante. Baseando-se no preceito de escuta via atenção flutuante, o clínico se depara com o surpreendente, por meio do relato daquilo que lhe capturou atenção, no qual se dá o trabalho de transformação de processos primários em secundários (Magtaz \& Berlinck, 2012).

Nessa direção, a interpretação de um caso acontece no trabalho de significação do que foi vivido na transferência. Diante dessa constatação, ao interpretar um caso, busca-se favorecer o pensamento metapsicológico com base na formulação de um problema de pesquisa e em um trabalho de associação por parte do clínico. Portanto o material clínico destina-se a uma transformação metapsicológica e ao questionamento do tema suscitado pela escuta do caso. Logo, segundo os autores, trata-se de

Pensar na construção de uma representação figurativa para o vivido da clínica (para o processo primário) como sendo uma elaboração secundária, uma interpretação ou a possibilidade mesma de transformar vivência em experiência socialmente compartilhada (Magtaz \& Berlinck, 2012, p. 78).

O intuito deste artigo é, portanto, refletir sobre uma situação clínica na qual a condição de escuta foi marcada pela repetição de relatos de violência oriunda da realidade externa a qual, ao ultrapassar as possibilidades do sujeito para sua metabolização, invade a realidade psíquica, provocando importantes fraturas na condição de ser da paciente em questão. Busca-se, assim, explorar as implicações na estruturação do sujeito psíquico de vivências da ordem do traumático as quais, repetidamente, marcam sua história. Trata-se de apresentar reflexões teóricas e técnicas a partir de uma experiência clínica.

\section{O CONTEXTO INTERSUBJETIVO: ENCONTROS SOB O IMPACTO DO EXCESSO}

Sabe-se que, quando não há alguém disponível tanto fisicamente quanto psiquicamente, na situação de encontro primordial, poderá haver comprometimento na organização psíquica infantil. Se, porventura, a mãe (ou um substituto) não puder dar conta das excitações da criança, em razão de suas próprias angústias ou fragilidades, essa situação pode se tornar arrasadora, acarretando danos permanentes no sentido da estruturação de um psiquismo 
que se constitui na condição de desespero e de invasão de intensidades psíquicas diante das quais não há possibilidades de auto-organização.

Para a psicanálise, o Eu é uma unidade psíquica que não está desde o início, e sua constituição mantém estreita relação com a qualidade do que lhe é ofertado a partir de fora (Freud, 1914). Dessa forma, o trajeto identificatório de um sujeito conta da modalidade e intensidades dos encontros que marcaram sua história (Hornstein, 1989). Uma vez que a estruturação do Eu ocorre a partir dos investimentos maternos que exercem sobre a criança uma modalidade necessária de violência simbólica, ou seja, apesar de a mãe se adequar às necessidades do bebê, o seu estilo é imposto via cuidados que outorga a ele. Assim, não há como evitar que a criança seja exposta a excessos, já que o discurso com o qual se depara é, por si só, uma realidade não compreensível. Portanto, constata-se que o ego surge "a partir de uma história preexistente, uma história identificatória" (Hornstein, 2008, p. 29).

As condições inaugurais do narcisismo da criança estão entrelaçadas à qualidade do investimento parental (figuras primordiais). Ao ser tomada como objeto de investimento amoroso por seus pais, inaugura-se a necessária condição de ilusão narcísica na qual a criança representa para estes um objeto catalisador de sua atenção e amor. Porém, nos casos nos quais o Eu não pode desfrutar das intensidades de prazer decorrente desses investimentos, configura-se um cenário de padecimento psíquico.

Segundo Moraes e Macedo (2011), os enunciados identificatórios que configuram o campo do traumático são impeditivos para o acesso à alteridade por parte do sujeito, capturando-o na repetição oriunda das intensidades vividas em sua história. Trata-se, portanto, de compreender o efeito do traumático como elemento presente no campo intersubjetivo no qual o sujeito recebe o que está aquém de suas demanda e necessidade para constituir-se como sujeito psíquico.

Eis que, na história de Marta, encontram-se elementos que auxiliam a reflexão sobre a temática do efeito do traumático na realidade psíquica. No desvelar de suas vivências no processo de escuta, Marta descortina os dramáticos efeitos de um excesso real de abandono e maus-tratos efetivamente experienciados. A paciente passou boa parte de sua infância em um abrigo sem ter conhecimento sobre quem era sua mãe biológica. Aos 8 anos, foi adotada por um casal que já tinha filhos. Nessa família, seu papel sempre foi claramente definido, era a empregada da casa. Costumava passar as férias na casa dos avós adotivos, situações nas quais o avô paterno abusava dela sexualmente. Nesse sentido, constata-se que, desde o princípio, a história de Marta está indelevelmente marcada por vivências de abandono, abuso e exploração. 
Autores pós-freudianos debruçaram-se sobre a importância da realidade externa no processo de constituição do psiquismo. Entre eles pode-se citar Donald Winnicott, que propôs uma teoria acerca da importância da qualidade da presença de um outro para que o desenvolvimento infantil ocorra de forma saudável. Em Winnicott (2005), o tema das falhas do ambiente em relação à criança é amplamente abordado. Com base em seu conceito de privação, o autor contribui para o entendimento da importância da realidade externa na constituição psíquica, abordando as consequências da ausência do outro como constituinte. Nesses casos, ao deparar-se com a falta dos cuidados em sua vida, diferentemente de se constituir livre, o sujeito passa a sentir-se aprisionado e impedido no acesso ao que lhe dá prazer.

$\mathrm{Na}$ perspectiva winnicottiana a respeito do desenvolvimento emocional, a realidade externa desempenha um papel vital, já que é a partir dos cuidados de um outro que o bebê se constitui e passa de um estado em que não se percebe separado do ambiente e no qual se mostra extremamente dependente do ambiente, para um outro estado no qual é possível sua independência (Winnicott, 1993). Assim, a carga pulsional oriunda das vivências primordiais da criança aos poucos precisa ser drenada por meio de recursos externos que aludem a ações que serão exercidas pela mãe suficientemente boa, ou seja, por aquela pessoa que assiste a criança em suas necessidades e, ao mesmo tempo, lida com seu ódio decorrente das necessárias frustraçôes desses momentos.

Winnicott (2005) também se ocupa dessa temática, ao introduzir o conceito de preocupação materna primária, o qual descreve a condição materna de sensibilidade exacerbada no período perinatal, ou seja, refere-se à capacidade de adaptação e de atenção da mãe às necessidades do recém-nascido. $\mathrm{O}$ autor afirma que há mulheres que não conseguem passar por esse estado de excluir outros interesses para atender às demandas do filho. Já as mães que conseguem ocupar essa condição possibilitam a construção de um ambiente favorável para que a criança comece a desenvolver sua constituição. Assim, o bebê pode ensaiar seus movimentos espontâneos e se apoderar das sensaçôes associadas a essa fase da vida. Essa mãe, portanto, promove uma situação condizente à "adaptação suficientemente boa” à demanda da criança.

Sabe-se que, no decorrer de seu desenvolvimento, a criança estará sujeita a intrusões advindas do ambiente, cabendo à mãe evitar que estas ocorram excessivamente. A falha materna no exercício de suas funções pode fomentar um excesso de perturbaçóes na vida da criança. Essas falhas maternas no reconhecimento das necessidades do seu bebê são codificadas como ameaças à existência, vividas como uma possibilidade de aniquilação do Eu (Winnicott, 2005). O bebê pode ou não se recuperar, porém, assegurado dessa condição 
de recuperação, poderá transformar a experiência em uma capacidade de lidar com frustraçôes. Cabe ressaltar, no entanto, que nem sempre o bebê terá essa capacidade.

A frequência de situações nas quais o excesso advindo do ambiente e as falhas maternas no sentido de proteção e cuidado ao filho deixa importantes marcas na história de Marta. Ao longo de sua infância, ela fica sujeita a repetidas experiências de extrema falta de cuidado. $\mathrm{O}$ papel de cuidador, que caberia às figuras primordiais desempenhar, no sentido de proteção do bebê, é falho na história da paciente. Nesse sentido, o abandono e a rejeição vão se refletindo em uma série de experiências, por exemplo, ser adotada, ao sair do orfanato, por uma família que dá continuidade às agressões e violências de toda ordem. Marta foi arrancada da condição de criança muito cedo. No engano da proposição de lugares, não ocupa o lugar de filha e passa a ser tratada como empregada. $\mathrm{Na}$ confusão e atordoamento gerados pela repetição do excesso, passa a desempenhar um papel de responsável pela casa e pelos cuidados das crianças que poderiam ser seus irmãos. Sua infância é permeada pela falta de cuidado, pela exigência do cumprimento de tarefas domésticas e pela falta de investimento afetivo por parte de seus pais adotivos. As obrigaçôes domésticas e as responsabilidades de cuidar do outro se estendem ao longo de sua adolescência e vida adulta, encobrindo, nas atividades de cuidado desempenhadas, as fraturas do descuido que experimenta repetidamente.

Marta traz em seu discurso a temática da servidão ao outro, sempre cumprindo exigências alheias como se estas fossem de sua responsabilidade: "É, eu me sinto responsável e culpada por tudo que está à minha volta. Me sinto responsável por eles. Acabo pegando pra mim um problema que não é meu. Por isso preciso de um afastamento, só que fico culpada em deixar eles sozinhos".

Associando proposições freudianas às contribuições de Winnicott (1975) a respeito da relevância de uma mãe suficientemente boa, cabe refletir sobre os danos causados no psiquismo de Marta decorrentes experiências traumáticas. Desde seus primeiros anos de vida, instaura-se um panorama de privaçôes que se estendem, posteriormente, ao longo de suas escolhas de vida. Marta busca o espaço analítico com o intuito de pensar-se. Atordoada desde dentro por intensidades psíquicas que não encontram vias de metabolização e elaboração, repete, em seu dia a dia, os excessos que a acompanham desde sempre. Sua condição de chegada à terapia parece assemelhar-se a experiência de caos em que se encontra um bebê não atendido em suas necessidades e, consequentemente, sem condiçõos psíquicas para aplacar as próprias excitações. Marta anuncia a modalidade transferencial que marcará seu percurso em busca de si mesma: 
Eu não sei explicar. Ando angustiada, deprimida, cansada. Sinto uma agonia, uma angústia. Sei lá, estou ansiosa. Tenho comido muito também. Eu me sinto muito mal, uma sensação ruim. Não aguento mais... É como se eu funcionasse no automático, não consigo pensar em nada. Essa confusão, é assim que eu me sinto, nessa bagunça. Eu não sei te explicar, hoje não sei dar nome pra isso que sinto, mas é assim que sinto. Por isso procurei ajuda.

Marta "descobre" estar grávida apenas aos cinco meses de sua segunda gestação, denunciando também a condição de não apropriação de seu corpo: "Já tinha certeza que estava grávida, mas consultei a médica para confirmar. Cheguei ao consultório e falei que eu achava que estava grávida, ela olhou para a minha barriga e começou a rir".

Esse fato evidencia a necessidade de Marta ser reconhecida por um outro que a nomeie e confirme sua percepção a respeito de si mesma. Ela não se (re) conhece como tendo um corpo físico, permeado por sensaçóes e reaçóes. Essa ausência de reconhecimento e apropriação do que lhe ocorre reproduz o sem lugar repetido em sua história. Marta tem graduação em História, mas trabalha com serviços de faxina, não sabe sobre sua verdadeira origem, é adotada como filha, mas exerce funções de empregada. A fragilidade das condições de olhar-se denuncia a ausência e precariedade no ter sido olhada e tomada como objeto de investimento amoroso via olhar de outro.

O não reconhecimento de si mesma repete-se ao referir os maus-tratos sofridos: "Fui pra casa dos meus pais adotivos e lá tinha que cuidar das crianças. Uma vez a minha mãe adotiva me bateu. Foi meio séria essa situação, ela dava com minha cabeça na parede". Na sequência, conta da repetição do excesso:

No orfanato, sempre me trancavam no quarto escuro, nossa! Como eu tinha medo de ir pra lá. Lembro também, uma vez, eu tive que ficar tanto tempo ajoelhada nas tampinhas que meus joelhos ficaram marcados por um bom tempo. Mas, fora isso, não me batiam.

O que chama a atenção nessa fala são a desconexão de afeto e a forma alheia como refere os próprios sentimentos. A falta do olhar leva a uma carência nas percepções internas e externas denominada por Hugo Bleichmar (1985) como déficit primário. $\mathrm{O}$ autor considera que, a partir dele, irá se produzir algo semelhante a uma parte insensível, a qual, se alguém não assinalar como inconveniente, o próprio sujeito não perceberá sua existência. 
Sob esse eixo temático que traduz uma anestesia em relação ao que lhe ocorre, ilustra-se a visão de Marta pelo olhar do ex-marido: "Uma vez, meu ex-marido foi lá em casa, me abraçou e me levou pra frente do espelho e disse o quanto eu me descuidei, que estava feia, gorda, e que minha aparência mudou pra pior". Ao longo dos encontros, complementa com os seguintes questionamentos: "Como eu pude me transformar nisso? Hoje não consigo nem pensar em me envolver com outra pessoa. Tenho medo de repetir isso tudo. Sempre que surge alguém, eu não invisto mais em mim".

As vivências traumáticas da história de Marta remetem à constatação provocada pelo excesso frequente que se incrementa nos prejuízos na condição de atribuições de sentido construídas em seu histórico vivencial e na condição de passividade que a paciente ilustra continuamente em suas falas. Observa-se em Marta uma obliteração de sua subjetivação, indicando outro estatuto do processo de narcisização: a desqualificação primária, na qual "o olhar crítico e o desprazer do outro significativo, desde o início da vida da criança, resultam na identificação desta com essa atitude" (Bleichmar, 1985, p. 92). Os registros mnêmicos dessas vivências de rejeição também constituem a representação que o sujeito faz de si, a qual preenche com algo que não é da ordem da ausência, do vazio, e sim com a presença ativa de seu contrário, da rejeição (Freud, 1914).

Marta tem parcas lembranças de sua vida antes do orfanato, as quais, no entanto, ecoam até hoje sobre sua visão de si e sob as modalidades de suas escolhas de objeto. Ela relata com muita emoção:

Eu nunca esqueço o dia da minha formatura. Eu me formei, tinha agradecido muito à minha família adotiva, falei isso na hora. Assim que eu desci do palco, minha mãe adotiva olhou pra mim e disse: "Agradece só ao tio Jorge, porque eu nunca acreditei em ti. Nunca acreditei que tu fosses chegar aqui". Ai, eu nunca esqueço disso. Doeu demais.

$\mathrm{Na}$ história de vida de Marta, são constantes os personagens que a tomam como objeto de satisfação narcísica. A paciente remonta uma cena infantil de um homem nu em sua cama tentando agarrá-la e tirando sua roupa. Depois somente lembra que fora para um orfanato. Após a adoção, Marta enfrentou novamente esse tipo de investimento abusivo por parte do avô e do tio-avô adotivos. $\mathrm{Na}$ época, Marta tinha 12 anos e lembra-se das carícias do avô adotivo. Do tio-avô, recorda-se das suas tentativas de agarrá-la. $\mathrm{O}$ ex-marido, segundo a paciente, sempre a "pegava à força”, chegando a machucá-la durante as relações sexuais. 
Ferenczi (1992), em seu texto Confusão de lingua entre os adultos e a criança, propõe uma compreensão para a produção de seduções incestuosas, na qual afirma que crianças têm fantasias lúdicas em relação ao adulto. Esse jogo entre o adulto e a criança que se amam mantém-se no nível da ternura, embora possa assumir uma maneira erótica. Porém adultos acometidos por tendências psicopatológicas confundem brincadeiras da ordem do infantil com desejos da ordem da maturidade sexual e acabam por inflingir práticas de atos sexuais sem medir efeitos. Ferenczi (1992) propõe a seguinte hipótese: "A personalidade ainda fracamente desenvolvida reage ao brusco desprazer, não pela defesa, mas pela identificação ansiosa e a introjeção daquele que a ameaça e a agride" (p. 103).

Também Ferenczi (1992) descreve o que considera ser mais uma forma de capturar uma criança, nomeando-o de terrorismo do sofrimento. Nessa situação, a criança é colocada como a responsável por resolver todo o tipo de problema familiar, carregando o peso de todos os membros da família. Constata-se que, em sua história, Marta, desde que fora adotada, serviu como um "pequeno auxiliar, um verdadeiro substituto materno" (Ferenczi, 1992, p. 105), posição em que a mãe adotiva a encarregava dos cuidados da casa e das outras crianças, sem levar em conta a condição infantil de Marta. Ao referir essa atribuição de tarefas além de suas condiçôes, Marta conta como se sentia:

Eu não chamava eles de pai e mãe, e sim de tio e tia. Nunca chamei eles de pai e mãe. Eles me pegaram do orfanato e sempre ficou claro que eu era a empregada deles. Eu que fazia tudo: limpava a casa, fazia comida, lavava a louça, cuidava das crianças. Hoje, só vou lá para fazer faxina, e eles me pagam pelo serviço.

A história de vida de Marta é permeada por experiências traumáticas, repletas de violência física e psíquica (maus-tratos, abusos, carência, desamparo, contexto familiar instável) que impediram a adequada tramitação e metabolização das intensidades dessas vivências em seu psiquismo. Para Freud (1917/1996), o trauma se dá por um excesso de excitação que o psiquismo do sujeito não é capaz de tolerar. Num primeiro momento, considera o traumático como um excesso de cunho essencialmente sexual, remetendo à cena real de sedução na infância. Posteriormente, esse conceito sofre uma complexização, uma vez que Freud abandona a ideia de que o trauma esteja unicamente ligado à cena real de abuso sexual. Dessa forma, as manifestações de padecimento psíquico podem ser pensadas sob diferentes pontos de vista e passa-se a atentar à importância do conceito de fantasia. 
O conceito de trauma proposto pela psicanálise não se restringe ao que tange à efetiva violência sexual advinda de experiências da realidade externa. $\mathrm{Na}$ ampliação do conceito, são contemplados os efeitos no psiquismo do excesso também advindo das experiências no campo da intersubjetividade, não necessariamente de situações de abuso sexual. O abandono da teoria da sedução por Freud (1895) e seus estudos sobre o trauma (Freud, 1920/1996) dão testemunho da ampliação que adquire o conceito de trauma para a psicanálise. Por isso, ao reconhecer os efeitos do traumático independente do fato real, é possível adentrar no campo da singularidade do sujeito e perceber a existência ou fragilidade de seus recursos intrapsíquicos para dar conta de algo da ordem do excesso.

Maia (2005) propõe importante diferenciação entre trauma subjetivante e trauma dessubjetivante. $\mathrm{Na}$ ampliação da definição de traumático, ele também passa a referir-se a um processo subjetivante, quando se refere às experiências que o infante enfrenta desde $\mathrm{o}$ ato de nascer, uma série de transformações quantitativa e qualitativamente intensas (Maia, 2005). Tal excesso invade o Eu, culminando em uma angústia impulsionadora à diferenciação do psiquismo diante do mundo externo. Nesse sentido, o traumático se dá na base da instauração dos processos psíquicos e não se tratando de um caráter dessubjetivante, mas sim constitutivo.

Conforme Maia (2005), o traumático desvela um cenário paradoxal, sendo gravemente perturbador, mas também é aquilo que abre a possibilidade de constituir-se como sujeito psíquico. A autora destaca a importância de considerar o campo intersubjetivo, uma vez que "o processo de afetação existente entre o sujeito e o mundo traz sempre em seu bojo um quantum de afetação traumática” (Maia, 2005, p. 115). Portanto, no que tange à constituição psíquica, o processo traumático é subjetivante se tal processo for marcado pelo ajustamento do mundo externo às necessidades do infante (Maia, 2005).

Aplacar as necessidades do bebê implica no apaziguamento da dor, que está na base dos processos de subjetivação. Entretanto, nesse intervalo entre a demanda e seu atendimento, o encontro pode se tornar um desencontro, uma não adequação do meio diante do desamparo do bebê. O descompasso frequente nesse campo relacional marcará uma vivência de excesso pulsional, e então o que era para ser da ordem do constitutivo passa a ter caráter dessubjetivante (Maia, 2005).

Faz-se necessário também atentar para marcas resultantes de outra modalidade de experiência que diz respeito à falha do objeto no atendimento das necessidades, quando existe uma "quantidade de excitação ou tensão de necessidade que confunde ao não se apresentar o objeto, já que, para que pudesse ser qualificada essa tensão quantitativa, seria necessária sua presença e 
compreensão" (Valls, 2004, p. 68). Essa ausência do objeto implica na tendência de reviver essa experiência de desvalia (Moraes \& Macedo, 2011). Conforme referido anteriormente, o encontro que institui as condições de estruturação do psiquismo requer do outro a capacidade de atender às demandas inerentes à condição de desamparo do bebê. Logo, diante desse contexto, o trauma tem extrema complexidade, uma vez que exige uma leitura profunda de sua relação com a intensidade não apaziguada em suas vivências primordiais e com as falhas no processo de construção de recursos (Moraes \& Macedo, 2011).

O acontecimento traumático, por sua intensidade, rompe com o que seria da ordem da sensatez e retira as possibilidades do sujeito no sentido da historicização do vivido de acordo com os recursos do sujeito. Para Moraes e Macedo (2011), o componente essencial do acontecimento traumático é seu efeito aprisionante, uma vez que o excesso não representado psiquicamente, na impossibilidade de atribuição de sentido, inunda o psiquismo. A instauração do traumático pode se dar pela indiferença experimentada no encontro com o semelhante. Tal acontecimento é permeado por forças e dramaticidade que as autoras nomeiam de vivência de indiferença. $\mathrm{O}$ termo vivência de indiferença dá conta da violência sofrida pela criança na sua estruturação psíquica, trata-se da ausência da oferta de ajuda alheia na medida em que o adulto não tenha a capacidade de realização de uma ação específica que atenda a demanda oriunda da condição de desamparo. $\mathrm{Na}$ definição proposta pelas autoras, a indiferença refere-se ao não reconhecimento da singularidade e das condições próprias à criança, ou seja, trata-se de importante prejuízo no campo da alteridade. $\mathrm{O}$ que fica no registro da indiferença diz respeito a fraturas no reconhecimento da própria existência do outro.

Nessa direção, Moraes e Macedo (2011) conceituam como vivência de indiferença a modalidade de encontro psíquico no qual a criança não encontra condições de reconhecimento e consideração à alteridade que a diferença de sua presença aporta ao outro. Tal vivência de excesso acarreta no desconhecimento do sujeito sobre si mesmo, trazendo como consequência a reprodução dessas intensidades destrutivas no campo intersubjetivo. As autoras referem a matriz de indiferença para descrever as situações de impossibilidades no campo da alteridade que se repetem na vida desses sujeitos a partir da situação experimentada de indiferença. $\mathrm{Na}$ repetição, Marta tenta se dar conta de um excesso de excitação no psiquismo, em uma tentativa de elaboração. Durante o processo de escuta, Marta reflete sobre suas experiências do passado, suas vivências de abuso, violência e exploração: "É, vai que eu arranjo um cara que nem meu ex-marido? No início, era tudo de bom, depois virou isso, só abuso e exploração". Em outro encontro, ela ilustra: "Eu não sei como fiquei com ele tanto tempo e ainda deixo ele 
fazer essas coisas. As vezes, eu fico pensando o quanto ele me maltratou e o quanto eu deixei ele fazer isso. Eu fui me largando até esse ponto".

Piera Aulagnier (1989) afirma que a identidade de um ser decorre da sua possibilidade de metabolizar os encontros relacionais que teve no momento da constituição do seu aparelho psíquico. Sem dúvida, a história de Marta permite constatar como os malefícios de um traumático encontro com o outro podem prejudicar o trajeto identificatório do sujeito e atrapalhar significativamente suas capacidades de superar conflitos e atribuir sentido ao que experimenta ao longo de sua vida.

\section{O ESPAÇO DE ESCUTA: CONSTRUÇÃO DE POSSIBILIDADES AO DEVIR}

Há uma queixa repetida sobre a ausência do outro na fala de Marta:

Eu sempre sofri sozinha, sempre me calei. Nunca soube dizer não, nunca respondi aos maus-tratos. Sempre guardei as coisas dentro de mim. Não sei dizer não. Não consigo dar limites. Eu sempre me calei para tudo o que aconteceu na minha vida, nunca falei.

As calas, ou seja, os buracos os quais desconhece, apontam para áreas do psiquismo que ainda não foram edificadas e bradam em silêncio, na desapropriação de si mesma, capturados em uma história desconhecida.

Com o tempo, Marta atravessa as fronteiras do inominável e rompe com o silêncio por vezes protetor, mas que a colocava numa posição de não existência. Marta reconhece o necessário movimento de apropriação de seus desejos para que possam ocorrer significativas transformações em sua vida. No processo de escuta, passa a acolher interrogaçooes sobre seu papel passivo diante da intensidade do vivido, demonstrando maior capacidade de expressar suas ideias e desejos nas suas relaçóes. No decorrer do processo, quanto mais recorre às palavras como recurso para dar sentido às intensidades que a assolam, sente-se menos angustiada e capaz de manter decisões e cumprir as próprias metas. $\mathrm{Na}$ modalidade transferencial, pode-se inaugurar uma relação diferente do que havia vivido sem a repetição do abuso e do abandono.

No que tange a seu processo de escuta diz:

Estar na terapia está sendo muito bom pra mim. Eu já me sinto bem melhor, estou diferente. Posso confiar em ti. Sei que tu não vai sair daqui e ficar fazendo fofoca, contando para os outros. Hoje eu vejo que preciso muito, até porque dá pra ver que eu estando bem já influencia a relação com as crianças. 
Marta rompe com a repetição de violência e descuido, passando a ter condições de investir na organização de uma nova rotina de vida. Os ganhos afetivos surgem na condição de se emocionar ao contar que começou a brincar com os filhos. Nos vazios da vida de Marta, o imperativo da passividade parecia ser a única forma de estar com o outro. Na brincadeira que experimenta junto aos filhos, ela exercita uma condição lúdica e prazerosa de propor ativamente algo ao outro no registro do prazer.

Conforme Maia (2005), o silêncio, por vezes, constitui-se como a única forma de continuar vivendo, manter guardado aquilo que não pode ser dito, nem mesmo para si. Os eventos traumáticos são "digeridos" sem elaboração e para sobreviver é necessário calar. Marta se calou para permanecer existindo. Tal silêncio lhe custou o preço da não existência reeditada em suas relaçôes atuais. O trabalho analítico então abre espaço para uma relação diferente, Marta está na condição de ser escutada, ou seja, é convidada a demandar algo a outro que acolhe e toma a palavra dela sobre si mesma no registro do valor e da confiança. Marta está ativa na condição de nomear sua dor para ser escutada, ou seja, no processo terapêutico, é convidada a existir em si mesma.

No momento em que procurou pela psicoterapia, tornou-se essencial recorrer à fala própria com o intuito de transformar a sua existência. Isso evidencia a presença de uma série de recursos egoicos em Marta que permitem não apenas uma sobrevivência física, mas a capacidade de usufruir de novos recursos psíquicos. Apesar de todos os abusos e maus-tratos, supõe-se que alguém se fez presente (como, por exemplo, o pai adotivo), sustentando um desejo para Marta com o qual ela pôde se identificar, ordenando parcialmente a desordem que as situações traumáticas acarretaram. Há em Marta a força de Eros produzindo ligaduras, sendo a propulsora da obtenção do diploma em História, da realização da maternidade e da busca por ajuda. A partir de reflexôes sobre sua existência, Marta passa a (re)pensar acerca de suas escolhas e dar-se conta das repetiçōes que a movem nessas modalidades de maus-tratos. Pelo desvelamento dos sentidos e intensidades dessas relaçóes entre o passado e seu presente, aos poucos consegue compreender sua parte envolvida nas formas como se relaciona com os objetos de sua história.

Ao falar sobre si mesma e ser escutada, Marta depara-se com a possibilidade de assumir sua vontade de conhecer sua origem, necessidade essa que permaneceu adormecida sob o atordoamento das experiências de abuso. Nesse sentido, a paciente elabora uma forma de dar vazão à curiosidade construída ao escutarse: Pensei em tentar procurar minha família, pensei em escrever no jornal, contar o que sei da minha história e ver se alguém sabe de algo. A partir das experiências de cuidado e do reconhecimento do valor do si mesmo que marcou o trabalho 
com Marta no espaço de escuta, ela busca possibilidades para pensar(-se). Ao se apropriar de sua condição ativa na produção de sua história, diz ela: Sempre que surge alguém, eu não invisto mais em mim.

No encontro com as condições próprias de um processo de escuta, a paciente apresenta a intensidade de uma história na qual o limite entre fantasia e realidade fica borrado pela ausência de cuidado e pelos excessos que se fazem presentes de forma repetida, criando lacunas e fraturas no processo de subjetivação de Marta. Nesses casos, mais do que vivências mal elaboradas pelo sujeito, fazemse presentes intensidades mortíferas decorrentes de um vazio representacional. O trabalho analítico possibilitou um trâmite dessas intensidades no espaço transferencial, oferecendo, ao mesmo tempo, a construção das condiçôes de atribuição de nexos e sentidos para um psiquismo carente de representaçôes.

\section{CONSIDERAÇŌEES FINAIS}

Desde o início de sua vida, a paciente viveu aprisionada à oferta de vivências de excesso, constituindo-se psiquicamente em um cenário de repetiçôes traumáticas que não lhe ofereciam diferentes alternativas, senão a de ocupar um lugar de desvalor e passivo diante do imposto por outro. Ao ser escutada, Marta inaugura condições para a possibilidade de construir uma história diferente. O campo analítico inaugura a condição de Marta experimentar um papel desconhecido e, ao mesmo tempo, almejado: ser uma historiadora, a tão desejada professora de História, mas, desta vez, ocupando-se da história de sua vida, não mais da prestação de serviço a outros. Inaugurou-se, na transferência, o acesso à capacidade de experimentar outra modalidade de encontro: a do cuidado.

Neste artigo, percebe-se ter sido a experiência de escuta que inaugurou uma possibilidade de atribuição de sentido a experiências de excesso que impediam Marta de pensar. Na condição ofertada para que Marta ocupe um lugar próprio, nomeando-se como protagonista de sua história, é dado início ao trabalho de atribuir sentido às intensidades que a aprisionavam na passividade repetida de servidão ao outro. Pode-se considerar que a realidade da análise, com elementos distintos do maltrato da história vivida, produz outra versão da história ao legitimar e resgatar o direito de auto-historicização e de ruptura com uma história na qual Marta estava desapropriada de si mesma. Diante dos relatos da indiferença sofrida, Marta, a protagonista desta história, inaugura no campo transferencial possibilidades de ingressar em um encontro marcado pelo reconhecimento da diferença que sua existência aporta. Diante das condições de sua realidade psíquica, as marcas de excesso da realidade externa podem ter outro destino que não mais o aprisionamento na repetição do descuido a si 
mesma. Assim, a psicanálise, com suas ferramentas, oferece ao sujeito psíquico as condições de criação e investimentos em formas de devir que possam ser traçadas a partir da autonomia e respeito ao si mesmo. 


\section{REFERÊNCIAS}

Aslan, C. M. (1996). Acerca de la estructura, la repeticiòn, la historia y la temporalidad. In L. G. Fiorini (Org.), Tiempo, historia y estructura: su impacto en el psicoanálisis contemporâneo (pp. 68-82). Buenos Aires: Lugar.

Aulagnier, P. (1989). Um intérprete em busca de sentido. São Paulo: Escuta.

Bleichmar, H. (1985). O narcisismo: estudo sobre a enunciação e a gramática inconsciente. Porto Alegre: Ledur.

Bleichmar, S. (2005). La subjetividad en riesgo. Buenos Aires: Topía.

Ferenczi, S. (1992). Confusão de língua entre os adultos e a criança. In A. Cabral (Ed. e Trad.), Obras completas. (Vol. 4, pp. 111-121). São Paulo: Martins Fontes. (Publicado originalmente em 1933)

Freud, S. (1895/1996). Projeto para uma psicologia científica. In J. Strachey (Ed. e Trad.), Edição standard brasileira das obras psicológicas completas. (Vol. 1, pp. 335-468). Rio de Janeiro: Imago. (Publicado originalmente em 1895)

Freud, S. (1897/1996). Extratos dos documentos dirigidos a Fliess. Carta 64. In J. Strachey (Ed. e Trad.), Edição standard brasileira das obras psicológicas completas. (Vol. 1, pp. 303-304). Rio de Janeiro: Imago. (Publicado originalmente em 1897).

Freud, S. (1914/1996). Sobre o narcisismo: uma introdução. In J. Strachey (Ed. e Trad.), Edição Standard Brasileira das obras psicológicas completas de Sigmund Freud. (Vol. 14, pp. 77-108). Rio de Janeiro: Imago. (Publicado originalmente em 1914).

Freud, S. (1917/1996). Conferência XVIII. Fixação em traumas: o inconsciente. In J. Strachey (Ed. e Trad.), Edição standard brasileira das obras psicológicas completas de Sigmund Freud. (Vol. 16, pp. 281-292). Rio de Janeiro: Imago. (Publicado originalmente em 1917).

Freud, S. (1920/1996). Além do princípio do prazer. In J. Strachey (Ed. e Trad.), Edição standard brasileira das obras psicológicas completas de Sigmund Freud. (Vol. 18, pp. 13-75). Rio de Janeiro: Imago. (Publicado originalmente em 1920).

Goldgrub, F. (1988). Trauma, amor e fantasia. São Paulo: Escuta. 
Hornstein, L. (1989). Introdução à psicanálise. São Paulo: Escuta.

Hornstein, L. (2008). As depressões: afetos e humores do viver. São Paulo: Via Lettera, Centro de Estudos Psicanalíticos.

Laplanche, J. \& Pontalis, J. P. (2010). Vocabulário de psicanálise. São Paulo: Martins Fontes.

Magtaz, A. C. \& Berlinck, M. T. (2012). O caso clínico como fundamento da pesquisa em psicopatologia fundamental. Revista Latinoamericana de Psicopatologia Fundamental, 15 (1), 71-81.

Maia, M. (2005). Extremos da alma. Rio de Janeiro: Garamond.

Moraes, E. G. \& Macedo, M. M. K. (2011). Vivência de indiferença: do trauma ao ato-dor. São Paulo: Casa do Psicólogo.

Valls, J. L. (2004). Metapsicologia y modernidad: el proyecto freudiano. Buenos Aires: Lugar.

Winnicott, D. (1993). Desenvolvimento emocional primitivo. In D. W. Winnicott, Textos selecionados: da pediatria à psicanálise. (pp. 269-285). Rio de Janeiro: Francisco Alves. (Publicado originalmente em 1945).

Winnicott, D. (2005). Privação e delinquência. São Paulo: Martins Fontes. (Publicado originalmente em 1956)

Winnicott, D. (1975). O brincar e a realidade. Rio de Janeiro: Imago. 